\title{
On the links between self-discrepancies, rumination, metacognitions, and symptoms of depression in undergraduates
}

Citation for published version (APA):

Roelofs, J., Papageorgiou, C., Gerber, R. D., Huibers, M. J. H., Peeters, F. P. M. L., \& Arntz, A. R. (2007). On the links between self-discrepancies, rumination, metacognitions, and symptoms of depression in undergraduates. Behaviour Research and Therapy, 45(6), 1295-305. https://doi.org/10.1016/j.brat.2006.10.005

Document status and date:

Published: 01/01/2007

DOI:

10.1016/j.brat.2006.10.005

Document Version:

Publisher's PDF, also known as Version of record

Document license:

Taverne

Please check the document version of this publication:

- A submitted manuscript is the version of the article upon submission and before peer-review. There can be important differences between the submitted version and the official published version of record.

People interested in the research are advised to contact the author for the final version of the publication, or visit the DOI to the publisher's website.

- The final author version and the galley proof are versions of the publication after peer review.

- The final published version features the final layout of the paper including the volume, issue and page numbers.

Link to publication

\footnotetext{
General rights rights.

- You may freely distribute the URL identifying the publication in the public portal. please follow below link for the End User Agreement:

www.umlib.nl/taverne-license

Take down policy

If you believe that this document breaches copyright please contact us at:

repository@maastrichtuniversity.nl

providing details and we will investigate your claim.
}

Copyright and moral rights for the publications made accessible in the public portal are retained by the authors and/or other copyright owners and it is a condition of accessing publications that users recognise and abide by the legal requirements associated with these

- Users may download and print one copy of any publication from the public portal for the purpose of private study or research.

- You may not further distribute the material or use it for any profit-making activity or commercial gain

If the publication is distributed under the terms of Article $25 \mathrm{fa}$ of the Dutch Copyright Act, indicated by the "Taverne" license above, 


\title{
On the links between self-discrepancies, rumination, metacognitions, and symptoms of depression in undergraduates
}

\author{
Jeffrey Roelofs ${ }^{\mathrm{a}, *}$, Costas Papageorgiou ${ }^{\mathrm{b}}$, Ralph D. Gerber ${ }^{\mathrm{a}}$, \\ Marcus Huibers ${ }^{\mathrm{a}}$, Frenk Peeters ${ }^{\mathrm{c}}$, Arnoud Arntz ${ }^{\mathrm{a}}$ \\ ${ }^{a}$ Department of Medical, Clinical, and Experimental Psychology, Maastricht University, The Netherlands. \\ ${ }^{\mathrm{b}}$ Institute of Health Research, University of Lancaster, UK. \\ ${ }^{\mathrm{c}}$ Department of Psychiatry, University Hospital Maastricht, The Netherlands
}

Received 27 May 2006; received in revised form 19 October 2006; accepted 25 October 2006

\begin{abstract}
The present study aimed to test the central components of Papageorgiou and Wells' (2003) non-clinical metacognitive model of rumination and depression that is grounded on the Self-Regulatory Executive Function (S-REF) model of emotional disorders [Wells, A., \& Matthews, G. (1994). Attention and emotion: A clinical perspective. Hove, UK: Lawrence Erlbaum.]. A second aim of this study was to extend the non-clinical model with the concept of self-discrepancy in line with the S-REF model. Data of the current study were collected in a large sample of non-clinical Dutch undergraduates $(N=196)$, who completed a battery of questionnaires including measures of rumination, positive and negative metacognitions, depressive symptoms, and self-discrepancy (i.e., actual-ideal, actual-ought, and actual-feared discrepancies). Hypothesized relationships among these variables were tested by means of structural equation modelling. Following some theoretically consistent modifications, the model was an adequate fit to the data. With respect to the second aim of the study, self-discrepancies were directly linked to symptoms of depression as well as indirectly via the cognitive processes involved in the metacognitive model of rumination and depression. Evidence was found for positive beliefs about rumination to partially mediate the relation between self-discrepancy and rumination. Clinical implications of the findings, including implementation of a metacognitive-focused cognitive therapy of depression, and suggestions for future research are discussed.
\end{abstract}

(C) 2006 Elsevier Ltd. All rights reserved.

Keywords: Depression; Rumination; Metacognitions; Self-discrepancy

\section{Introduction}

Rumination, defined as self-focused, persistent, recurrent, negative thinking, has attracted increasing theoretical and empirical interest in the past decade (Papageorgiou \& Wells, 2004). Several correlational, experimental, and longitudinal studies have linked rumination to longer and more severe periods of depressed mood (For comprehensive reviews, see Nolen-Hoeksema, 1998; Lyubomirsky \& Tkach, 2004). Rumination

*Corresponding author. Tel.: + 3143 3881607; fax: + 31433884155 .

E-mail address: J.Roelofs@dep.unimaas.nl (J. Roelofs). 
appears to serve the perceived functions of attaining certain goals (i.e., reduction of discrepancies) and gaining insight (Martin \& Tesser, 1996; Nolen-Hoeksema, 1991; Papageorgiou \& Wells, 2001a, b). Identification of beliefs about rumination (i.e., metacognitions) may further contribute to the understanding of the perceived functions of rumination. An important step in this direction has been the development of specific metacognitive models of rumination and depression (e.g., Papageorgiou \& Wells, 2003, 2004), which are grounded in the Self-Regulatory Executive Function (S-REF) model of psychological disorders (Wells \& Matthews, 1994).

\section{The S-REF model and the development of metacognitive models of rumination and depression}

The S-REF model is a generic information processing and metacognitive model, which postulates that emotionally vulnerable individuals engage in ruminative thinking or worrying as a function of underlying metacognitive beliefs concerning its functions and consequences. In this model, rumination and worry can contribute directly to emotional disturbance (e.g., by prolonging it) and also indirectly through negative metacognitions (e.g., by increasing threatening appraisals of thoughts and emotions). More precisely, positive metacognitive beliefs (e.g., "Ruminating will help me cope") initiate and perpetuate perseverative negative thinking and negative metacognitive beliefs (e.g., "I have no control over my thoughts") contribute a link between perseverative negative thinking and emotional disorders (Wells \& Matthews, 1994).

Drawing on the S-REF model, Papageorgiou and Wells $(2003,2004)$ have outlined a clinical metacognitive model of rumination and depression as well as a non-clinical version of this model. In their clinical model, they postulate that positive metacognitions initiate rumination. More specifically, positive metacognitions are beliefs that rumination is a helpful coping strategy for reducing discrepancies between a present state and a desired (target) state (e.g., "In order to understand my feelings of depression I need to ruminate about my problems"). However, when rumination fails to reduce this discrepancy, it may lead to ruminative thoughts, lowering of mood, and interference with effective problem solving. As a consequence, negative metacognitions may emerge. This type of metacognition can be divided into beliefs concerning the uncontrollability and harmfulness of rumination (e.g., "Ruminating means I'm out of control") and beliefs about the interpersonal and social consequences of rumination (e.g., "People will reject me if I ruminate"). These negative metacognitions are hypothesized to contribute to depression. Finally, decreases in confidence in cognitive functioning, which Papageorgiou and Wells $(2003,2004)$ view as a depressogenic by-product, might contribute to negative beliefs about interpersonal and social consequences of rumination as well as positive beliefs concerning the need to ruminate in order to facilitate effective coping.

Empirical evidence has demonstrated that both positive and negative beliefs about rumination are linked to rumination and depression in non-clinical samples as well as in samples of clinically depressed patients (Papageorgiou \& Wells, 2001a, b, 2003). An initial study by Papageorgiou and Wells (2003) tested the metacognitive model of rumination and depression in a large clinical sample and explored its validity in a nonclinical sample by means of structural equation modelling. Results indicated that the central hypothesized links in the clinical sample were indeed confirmed but an additional path had to be introduced and another removed to achieve good model fit in the non-clinical sample. A difference between both samples was found with respect to metacognitions concerning uncontrollability and harm, which was unrelated to depressive symptomatology in non-clinical individuals, but did show a positive relationship in clinically depressed individuals. Moreover, in the non-clinical sample, rumination was found to lead to symptoms of depression either directly or indirectly via negative metacognitive beliefs about the interpersonal and social consequences of ruminating (Papageorgiou \& Wells, 2003, Study 2). However, in the clinical sample, rumination led to symptoms of depression only indirectly via both domains of negative metacognitions (Papageorgiou \& Wells, 2003, Study 1). It should also be noted that beliefs concerning confidence in cognitive functioning were also assessed, but in contrast to the depressed sample, these beliefs were not linked to the variables in the model in the non-clinical sample. These results suggest that positive beliefs about rumination are closely linked to a tendency to ruminate in response to depressed mood in both clinical and non-clinical samples. Negative beliefs about rumination seem to serve a key function, fully (clinical model) or partly (non-clinical model), mediating the relationship between rumination and depressive symptoms. Taken together, despite there being relatively 
few studies conducted so far, there is some evidence to suggest that metacognitions and rumination are indeed key features in depression.

An important tenet of the S-REF model is that it postulates that positive metacognitions lead to perseverative negative thinking as an attempt to reduce discrepancies between present and desired states. Indeed, Wells and Matthews (1994) argued that if "a negative self-discrepancy persists, leading to dysphoria and anxiety, there is an increased likelihood of S-REF perseveration and subsequent activation of the dysfunctional cognitive-attentional syndrome" (p. 335). However, no research has linked self-discrepancy to metacognitive models of rumination and depression. Our aim in this study was to test a model with such a link as specified in the S-REF model.

\section{Self-discrepancy theory}

Self-discrepancy theory (SDT; Higgins, 1987), which has its roots in social psychology, might provide an important and valuable theoretical framework to connect self-discrepancy to metacognitive models of rumination and depression. According to SDT, individuals have three basic domains of selves: the actual self (e.g., the individuals' perception of his or her actual attributes and characteristics), the ideal self (e.g., the attributes of an individual which he or she hopes to possess or aspires), and the ought self (e.g., attributes an individual should have). SDT assumes that discrepancies between selves give rise to specific negative emotions (Higgins, 1987; Higgins, Roney, Crowe, \& Hymes, 1994). More specifically, a discrepancy between the actual self and the ideal self is assumed to give rise to dejection-related emotions (e.g., disappointment, frustration), whereas a discrepancy between the actual self and the ought self is hypothesized to lead to agitation-related emotions (e.g., guilt, self-contempt). SDT assumes that individuals are motivated to work towards a condition where the actual self matches the ideal and/or ought self. However, SDT does not specify the nature of this condition whereas the S-REF model suggests that self-knowledge, which includes metacognitions, activates perseverative thinking in the form of rumination/worry, as a means of coping with the discrepancy.

Although numerous studies have found support for the specific discrepancy-emotion predictions of SDT (e.g., Higgins, 1987, 1999; Higgins, Bond, Klein, \& Strauman, 1986; Higgins, Shah, \& Friedman, 1997; Moretti \& Higgins, 1990; Scott \& O'Hara, 1993; Strauman, 1989), other studies have failed to find evidence for these links (e.g., Bruch, Rivet, \& Laurenti, 2000; Tangney, Neidenthal, Covert, \& Barlow, 1998). Selfdiscrepancies have also been implicated in clinical disorders such as depression and anxiety (e.g., Scott \& O'Hara, 1993; Strauman, 1989). Markus and Nurius (1986) introduced the concept of the feared self, which refers to the self that an individual wants not to become and closely resembles the concept of the undesired self as proposed by Ogilvie (1987). In connecting SDT to metacognitive models of rumination and depression, it may be hypothesized that the emergence of positive metacognitions about rumination and subsequent ruminative thoughts are ways to reduce perceived self-discrepancies.

\section{The present study}

The aims of the present study were twofold. First, we set out to test the central components of Papageorgiou and Wells' (2003) non-clinical metacognitive model of rumination and depression (i.e., proposed associations between positive metacognitions, rumination, negative metacognitions, and depressive symptoms) in a large sample of Dutch undergraduates. Fig. 1 presents a graphical representation of the model that Papageorgiou and Wells (2003) used to develop their clinical and non-clinical metacognitive models of rumination and depression. Second, the model was extended with self-discrepancies in line with the S-REF framework. More specifically, we examined the degree to which the cognitive processes involved in the metacognitive models of rumination and depression (i.e., positive metacognitions, rumination, and negative metacognitions) were responsible for mediating the relationship between self-discrepancy and depression. As positive metacognitions and subsequent rumination are considered mechanisms to reduce the impact of self-discrepancies on the emotional state of individuals, it might be hypothesized that self-discrepancy exerts its influence directly upon the positive metacognitions. Moreover, it might be expected that positive metacognitions mediate the relation between self-discrepancy and rumination. We did not have clear expectations about what type of selfdiscrepancy would be most strongly associated with symptoms of depression. Therefore, the contribution of 


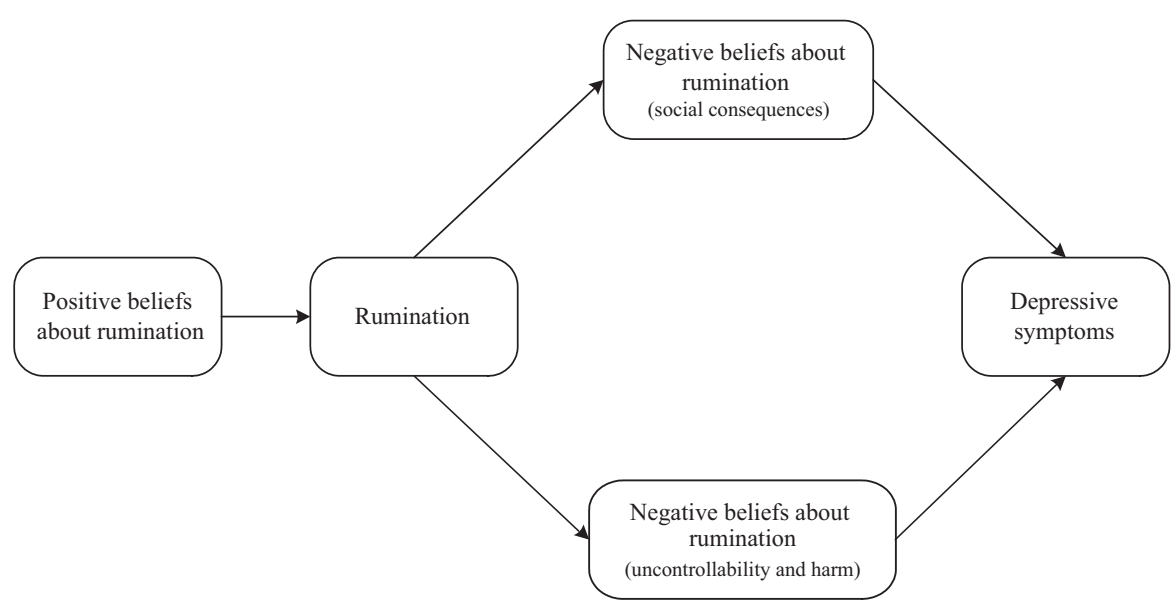

Fig. 1. Graphical representation of the central components of the metacognitive model of rumination and depression (Papageorgiou \& Wells, 2003, 2004).

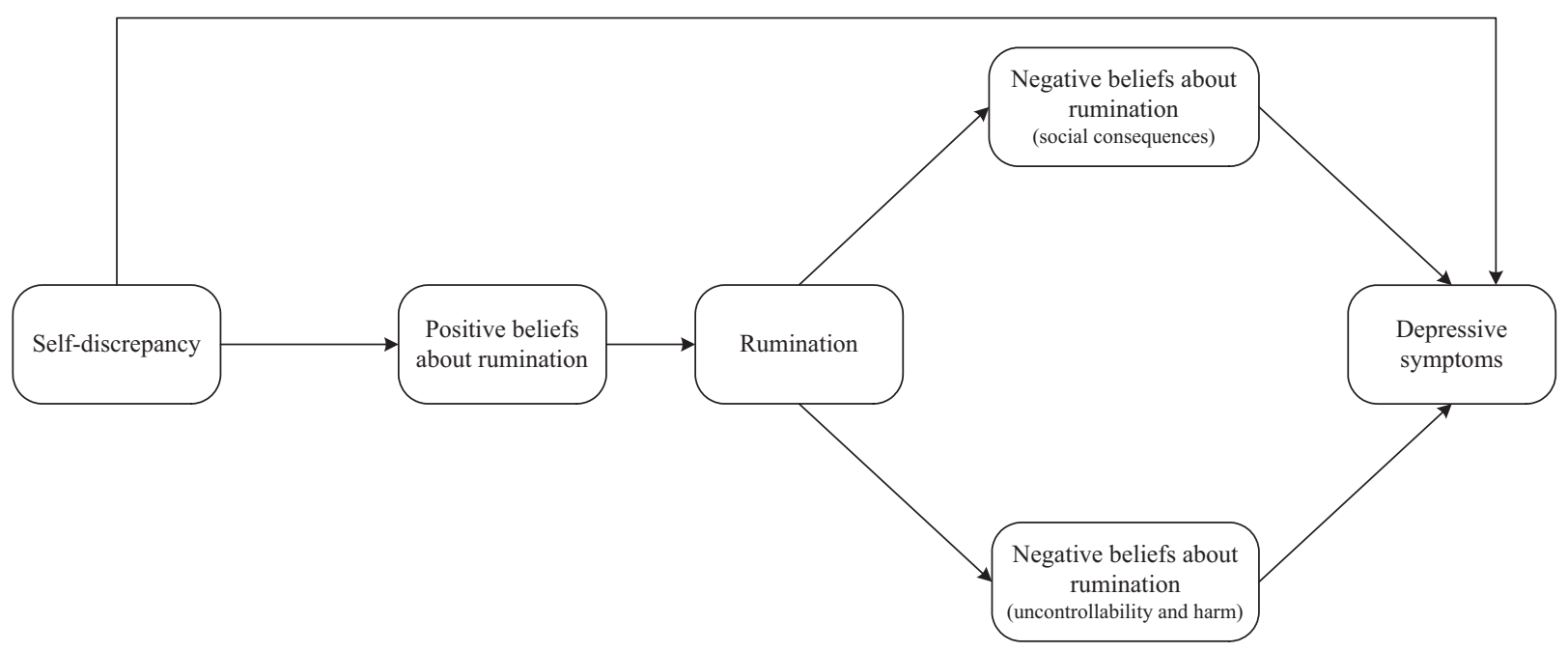

Fig. 2. Proposed relationships of self-discrepancy in the metacognitive model of rumination and depression.

self-discrepancy to metacognitive models of rumination and depression was examined in an exploratory manner. Furthermore, consistent with Papageorgiou and Wells (2003), it was hypothesized that negative metacognitions mediate the relationship between rumination and depression. As SDT assumes a direct link between self-discrepancy and depression, we completed tests of the model by linking self-discrepancy to depression. Fig. 2 depicts a graphical representation of the hypothesized relationships in metacognitive models of rumination and depression.

\section{Method}

\section{Participants and procedure}

A total of 196 undergraduates (36 males, 160 females) of Maastricht University (The Netherlands) voluntarily participated in this study. Mean age of the sample was 21.4 years ( $S D=2.5$, range: $18-28$ years). No exact information about participants' ethnicity was available but the vast majority of the individuals were Caucasian (more than 95\%). Individuals were compensated for their participation by class credit and having 
the opportunity to win 25 Euros (10 individuals of the total sample) in a lottery. Written consent was obtained from all participants before the start of the study. All participants completed a set of questionnaires (see measures) in a counterbalanced order. Respondents completed the measures in a conference room in groups of 5 to 10 students. A research assistant was always available to provide assistance and to ensure confidential and independent responding.

\section{Measures}

Quick Inventory of Depressive Symptomatology (QIDS; Rush et al., 2003)

The QIDS is a 16-item self-report measure of depressive symptomatology aimed to assess DSM-IV diagnostic criterion items for major depressive disorder (e.g., mood, concentration, self-criticism, suicidal ideation, interest, energy/fatigue, sleep disturbance, decrease/increase in appetite/weight, and psychomotor agitation/retardation). Items are rated from the prior 7 days and are scored on a scale from 0 to 3 . The total score ranges from 0 to 48. Reliability and validity of the QIDS are well documented (see Rush et al., 2003).

\section{Ruminative Response Scale (RRS; Nolen-Hoeksema \& Morrow, 1991)}

The RRS includes 22 items assessing individual differences in response to sadness or depressed mood (e.g., "I think about how alone I feel"). Respondents are requested to indicate how often they engage in each of these responses using a four-point Likert-type scale ranging from 1 (almost never) to 4 (almost always). Total rumination scores range from 22 to 88 . The RRS is a reliable and valid measure of rumination (Raes, Hermans, \& Eelen, 2003; Luminet, 2004).

\section{Positive Beliefs about Rumination Scale (PBRS; Papageorgiou \& Wells, 2001b)}

The PBRS is a nine-item scale assessing positive metacognitive beliefs about rumination (e.g., "I need to ruminate about my problems to find answers to my depression"). Respondents are asked to indicate the extent to which they agree with each of the items on a four-point Likert-type scale ranging from 1 (do not agree) to 4 (agree very much). Total scores range between 9 and 36. The PBRS was translated into Dutch for the purpose of the present study. Reliability and validity of the PBRS are good (Papageorgiou \& Wells, 2001a, b).

\section{Negative Beliefs about Rumination (NBRS; Papageorgiou \& Wells, 2001a)}

The NBRS is a 13-item questionnaire tapping negative metacognitive beliefs about rumination and comprises two subscales. The first scale assesses metacognitive beliefs about uncontrollability and harm associated with rumination (e.g., "Ruminating about my problems is uncontrollable"). The second scale measures metacognitive beliefs about interpersonal and social consequences of rumination (e.g., "Rumination means I'm a bad person"). Respondents are asked to indicate the extent to which they agree with each of the items on a four-point Likert-type rating scale ranging from 1 (do not agree) to 4 (agree very much). The total scores range from 13 to 52. The NBRS was translated into Dutch for the purpose of the present study. Reliability and validity of the NBRS are good (Papageorgiou \& Wells, 2001a; Luminet, 2004).

\section{Miskimins Self-Goal Other Discrepancy Scale (MSGO; Miskimins \& Braucht, 1971)}

The MSGO is a 15-item measure of self-discrepancy, which was adapted in the current study to tap actualideal, actual-ought, and actual-feared discrepancies. Each scale consisted of 15 pairs of constructs (e.g., "happy" and "sad"), which had to be rated on 9-point Likert-type scales. Of interest were not the absolute ratings, but the differences or discrepancies between the actual-self ratings and the other three. For ideal, ought, and feared discrepancy, actual-self scores were subtracted from ideal and ought ratings, respectively. As such, higher scores of discrepancies reflect higher self-discrepancies. A paper currently in preparation provides support for the reliability and validity of this questionnaire. That is, internal consistency ratings (alphas ranged between .81 and .89) are good and substantial and positive relationships were found with comparable measures such as self-liking and competence, and self-esteem. 


\section{Statistical analyses}

The Statistical Package for Social Sciences (SPSS version 12.0) was used for computing descriptive statistics, correlations, carrying out $t$-tests (i.e., to explore gender differences on the questionnaire scores), and regression analyses (for the purpose of the mediation analyses). Mediation was examined in accordance with the guidelines provided by Baron and Kenny (1986). Sobel's $t$ was used to test for the significance of the mediation effect (Sobel, 1982).

LISREL (Jöreskog \& Sörbom, 1999, version 8.30) was used for structural equation modelling in order to evaluate the fit of the hypothesized associations between positive metacognitions, rumination, negative metacognitions, and depressive symptoms that constitute the central components of metacognitive models of rumination and depression and to link self-discrepancies to the model. LISREL provides a series of fit indices that allow for an estimation of how good the specified model fits to the data: (a) minimum fit function chi-square; (b) Root Mean Square Error of Approximation (RMSEA); (c) the Comparative Fit Index (CFI); and (d) the Non-Normed Fit Index (NNFI). The minimum fit function chi-square represents the distance between the model specified and the saturated model (a model in which the maximum number of parameters is estimated). The chi-square value should be non-significant, indicating that the model does not differ significantly from the saturated model. For the RMSEA, values below .05 or lower to indicate a close fit, whereas values up to .08 represent reasonable errors of approximation. For the CFI and NNFI, values above .90 are indicative of a good fit whereas values above .95 are indicative of a very good fit. In the case of inadequate fit of the model to the data, modification indices provided by LISREL were inspected. These indices provide information with respect to the changes that need to be made to the model (e.g., adding or removing a path, setting free error covariances) in order to obtain a good fit to the data.

\section{Results}

\section{General findings}

Table 1 presents general descriptive statistics, ratings of internal consistency (Cronbach's $\alpha$ s), and a correlation matrix of the questionnaires used in the current study. Before addressing the main results, three remarks with respect to the results presented in Table 1 are in order. First, depression scores (QIDS) and scores on the negative beliefs about rumination scales (NBRS) were transformed to a normal distribution as the data were positively skewed (range skewness: 2.35-9.23). A root-square transformation was applied to

Table 1

Descriptive statistics, internal consistency ratings (Cronbach's $\alpha$ s), and correlations of the questionnaires $(N=196)$

\begin{tabular}{|c|c|c|c|c|c|c|c|c|c|c|}
\hline Self-report measures & Mean & SD & $\alpha$ & 1. & 2. & 3. & 4. & 5. & 6. & 7. \\
\hline 1. Depression (QIDS) & 6.6 & 5.2 & .78 & - & & & & & & \\
\hline 2. Rumination (RRS) & 40.7 & 11.1 & .91 & $.32 * *$ & - & & & & & \\
\hline 3. Positive metacognitions (PBRS) & 16.1 & 5.4 & .89 & $.31 * *$ & $.55^{* *}$ & & & & & \\
\hline \multicolumn{11}{|l|}{ Negative metacognitions (NBRS): } \\
\hline 4. Social consequences & 6.1 & 1.9 & .74 & .14 & .17 & $.20 *$ & - & & & \\
\hline 5. Uncontrollability and harm & 11.4 & 3.5 & .79 & $.26^{* *}$ & $.30 * *$ & $.35^{* *}$ & $.53 * *$ & - & & \\
\hline \multicolumn{11}{|l|}{ Self-discrepancy (MSGO): } \\
\hline 6. Actual-ideal discrepancy & 22.1 & 11.6 & .77 & $.30 * *$ & $.23^{*}$ & .17 & .10 & .12 & - & \\
\hline 7. Actual-ought discrepancy & 14.1 & 14.7 & .82 & $.39 * *$ & $.22 *$ & $.21^{*}$ & .08 & .13 & $.59 * *$ & - \\
\hline 8. Actual-feared discrepancy & 75.2 & 17.1 & .85 & $.28 * *$ & $.21^{*}$ & $.28^{* *}$ & $.18 *$ & $.25^{* *}$ & $.44 * *$ & $.32 * *$ \\
\hline
\end{tabular}

Note: QIDS = Quick Inventory of Depressive Symptomatology; RRS = Ruminative Response Scale; PBRS = Positive Beliefs about Rumination Scale; NBRS = Negative Beliefs about Rumination Scale; MSGO = Miskimins Self-Goal Other Discrepancy Scale. ${ }^{*} p<.01$; $* * p<.001$. 
scores on the negative beliefs about rumination (social consequences scale) while a logarithmic transformation was used for depression scores and scores on the negative beliefs about rumination (uncontrollability and harm scale). All variables were standardized for the purpose of structural equation modelling. Second, $t$-tests revealed no gender differences on each of the self-report measures (alpha was set to .01 to control for Type I error). Third, the social consequences subscale of the negative beliefs about rumination scale showed no significant associations with rumination and depression, which is inconsistent with previous findings (e.g., Papageorgiou \& Wells, 2001b, 2003).

\section{Goodness-of-fit of the metacognitive model of rumination and depression}

Structural equation modelling indicated that the model as depicted in Fig. 1 showed no good fit to the data $\chi^{2}(5, N=196)=85.9, p<.01$, RMSEA $=.28, \mathrm{CFI}=.62, \mathrm{NNFI}=.24$, which is consistent with the initial results reported by Papageorgiou and Wells (2003, Study 2) in their non-clinical sample. The modification indices provided by LISREL indicated improvements to the fit of the model to the data by adding the path between rumination and depression, removing the path between NBRS social consequences and depression, letting the relationship between rumination and NBRS uncontrollability and harm be reciprocal, and setting the error covariance between both NBRS scales free. With respect to the latter modification, both NBRS scales may have something in common in addition to the shared variance between these scales. This is not surprising as both scales belong to the same questionnaire. These modifications resulted in a model that fitted very well to the data, $\chi^{2}(3, N=196)=13.7, p>.05, \mathrm{RMSEA}=.073, \mathrm{CFI}=.99, \mathrm{NNFI}=.95$. Fig. 3 presents a graphical representation of the resulting non-clinical metacognitive model of rumination and depression, including the abovementioned modifications.

The metacognitive model of rumination and depression predicts that negative beliefs about rumination mediate the relationship between rumination and depressive symptoms. However, mediation implicates that a mediator transmits the effects of an independent variable to a dependent variable thereby assuming unidirectional relationships, which was not the case for the relation between rumination and NBRS uncontrollability and harm. Nevertheless, it is possible to examine the relative contribution of rumination and NBRS uncontrollability and harm to explaining variance in depressive symptoms. Two separate regression analyses revealed that rumination $(\beta=.32, \mathrm{SE}=.07, p<.001)$ and NBRS uncontrollability and harm $(\beta=.26, \mathrm{SE}=.07, p<.001)$ in isolation were linked to depressive symptoms. When both predictors were simultaneously taken into analysis, rumination and NBRS uncontrollability and harm still explained a significant proportion of the variance $(\beta=.27, \mathrm{SE}=.07, p<.001$ and $\beta=.18, \mathrm{SE}=.07, p=.01$, respectively).

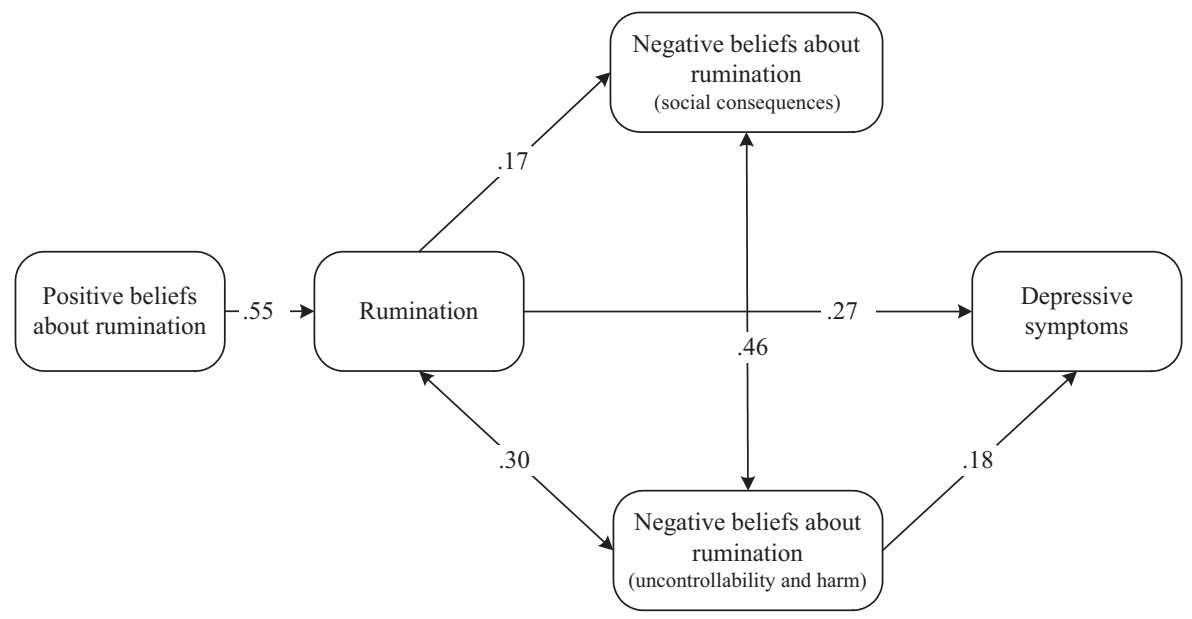

Fig. 3. Structural equation modelling of the metacognitive model of rumination and depression. 


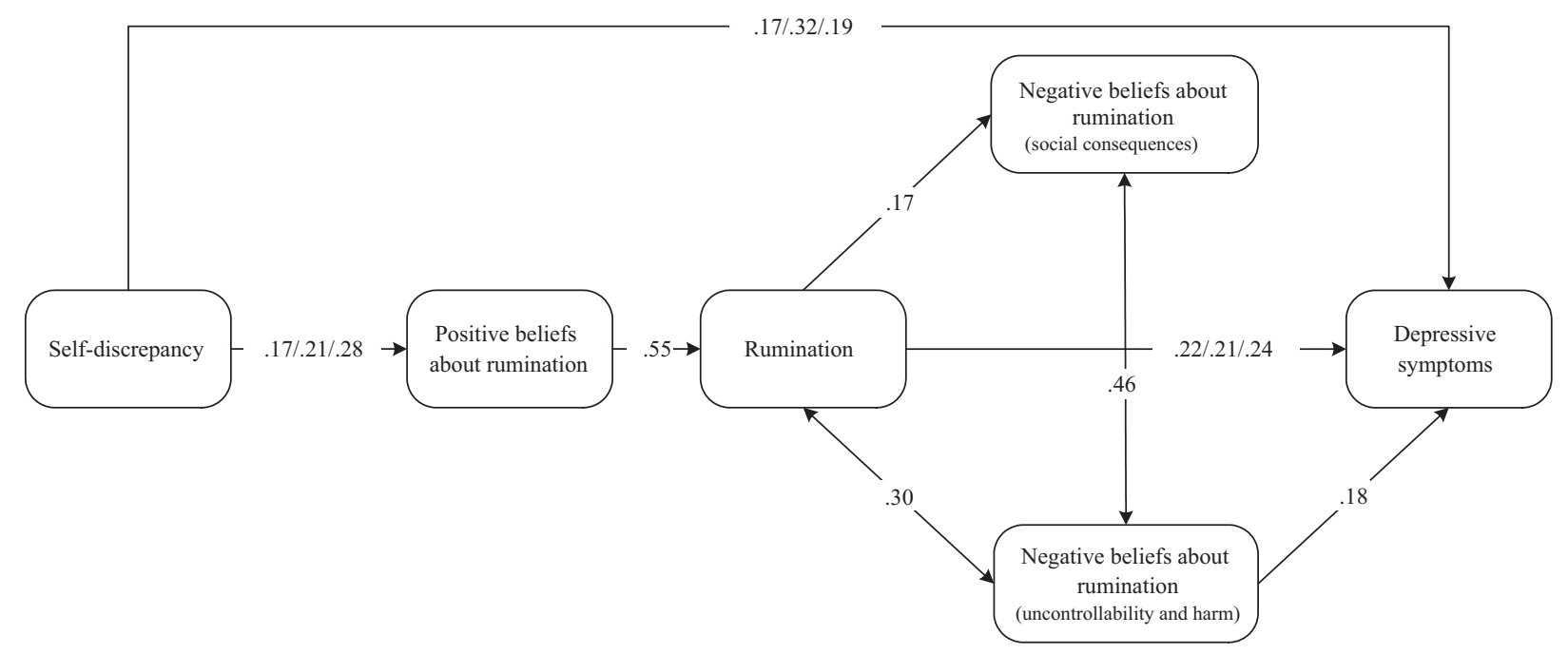

Fig. 4. Structural equation modelling of self-discrepancies (ideal/ought/feared respectively) in the metacognitive model of rumination and depression.

\section{Self-discrepancies and the metacognitive model of rumination and depression}

The hypothesized influences of self-discrepancies on positive metacognitive beliefs about rumination and symptoms of depression were investigated. In three separate analyses, actual-ideal, actual-ought, and actualfeared discrepancies were added to the resulting non-clinical model. A good fit of the model to the data was found for all tested models. More specifically, after including actual-ideal self-discrepancy to the model the goodness-of-fit indices indicated good fit: $\chi^{2}(6, N=196)=12.4, p>.05$, RMSEA $=.072, \mathrm{CFI}=.97$, $\mathrm{NNFI}=.93$. For the inclusion of actual-ought discrepancy a very good fit was found, $\chi^{2}(6, N=196)=8.3$, $p>.05, \mathrm{RMSEA}=.043, \mathrm{CFI}=.99, \mathrm{NNFI}=.98$, while good fit was also found when actual-feared discrepancy was added to the model, $\chi^{2}(6, N=196)=11.5, p>.05$, RMSEA $=.074$, CFI $=.98$, $\mathrm{NNFI}=.95$. Fig. 4 presents a graphical representation of the links between self-discrepancies and the metacognitive model of rumination and depression.

It was further hypothesized that positive beliefs about rumination would mediate the relation between selfdiscrepancy and rumination. Mediation was examined in accordance with the guidelines provided by Baron and Kenny (1986) and Sobel's $t$-test was used to test the significance of mediation. Assessing mediation can be achieved in three steps (see Baron \& Kenny, 1986). In the first step, the mediator (positive beliefs about rumination) was regressed on the independent variable (self-discrepancy), whereas in the second step, the dependent variable (rumination) was regressed on the independent variable. In the final step, the dependent variable was regressed on the independent variable and the mediator. Mediation is established when the relation between the independent variable and the dependent variable drops substantially when the mediator is taken into analyses. Results of the three consecutive regression analyses that are involved in examining mediation are presented in Table 2 and suggest partial but significant mediation of positive beliefs about rumination actual-ideal discrepancy (Sobel's $t=2.30, p=.02$ ), actual-ought discrepancy (Sobel's $t=2.88$, $p=.004$ ), and actual-feared discrepancy (Sobel's $t=3.74, p<.001$ ).

\section{Discussion}

The present study sought to test out the central components of Papageorgiou and Wells' (2003) non-clinical metacognitive model of rumination and depression (i.e., hypothesized associations between positive metacognitions, rumination, negative metacognitions, and depressive symptoms) in a large sample of Dutch undergraduate students. The current study also attempted to extend this model with the concept of selfdiscrepancy to bring it further in line with Wells and Matthews' (1994) S-REF model. Positive metacognitive 
Table 2

Standardized regression coefficients for examining mediation of positive beliefs about rumination (PBRS) between self-discrepancy (MSGO) and rumination (RRS)

\begin{tabular}{|c|c|c|c|c|c|c|c|c|}
\hline \multirow[t]{3}{*}{ Step } & \multirow[t]{3}{*}{ Dependent } & \multirow[t]{3}{*}{ Independent } & \multicolumn{6}{|c|}{ Self-discrepancy } \\
\hline & & & \multicolumn{2}{|c|}{ Actual-ideal } & \multicolumn{2}{|c|}{ Actual-ought } & \multicolumn{2}{|c|}{ Actual-feared } \\
\hline & & & $\beta$ & SE & $\beta$ & SE & $\beta$ & SE \\
\hline 1. & PBRS & MSGO & .17 & .07 & .21 & .07 & .28 & .07 \\
\hline 2. & RRS & MSGO & .23 & .07 & .22 & .07 & .21 & .07 \\
\hline \multirow[t]{2}{*}{3.} & RRS & MSGO & .15 & .06 & .11 & .06 & .06 & .06 \\
\hline & & PBRS & .52 & .06 & .53 & .06 & .53 & .06 \\
\hline
\end{tabular}

Note $:$ RRS = Ruminative Response Scale; PBRS = Positive Beliefs about Rumination Scale; MSGO= Miskimins Self-Goal Other Discrepancy Scale.

beliefs about rumination were expected to mediate the relation between self-discrepancy and rumination and negative beliefs about rumination were hypothesized to mediate the relation between rumination and depression. Finally, a direct link from self-discrepancy to depression was hypothesized.

The fit of the model depicted in Fig. 1 was inadequate, leaving room for improvement of the model in order to obtain an adequate fit of the model to the data. This finding concurs with that of Papageorgiou and Wells (2003, Study 2) who also found that this model did not fit in their non-clinical sample. However, they found that a direct link between rumination and depression and a link mediated by negative metacognitions provided a model that did fit the data. The findings of the present study are consistent with this, with the only difference being the nature of the negative metacognition subscales providing the mediating link. These data are consistent with the direct and indirect effects predicted by the S-REF model. Why should the results of Papageorgiou and Wells' (2003) study and those of the current study present different negative metacognitions as mediators? This may be the result of use of a different measure of depression in each study, the potential influence of cultural differences between the samples, the translational nature of the NBRS, and the fact that Papageorgiou and Wells (2003) incorporated cognitive confidence in their analyses whereas we did not measure and include this construct in our analyses. Clearly, future research is warranted to further elucidate the exact nature of the link between negative beliefs about rumination and depression.

Results showed that the relation between rumination and NBRS uncontrollability and harm was reciprocal. As such, rumination is not only linked to NBRS uncontrollability and harm, but the latter variable may in turn give rise to ruminative thoughts, thereby reinforcing ruminative thinking. An individual who is in the rumination mode could repetitively think about the threatening consequences of this process and try to anticipate or avoid these consequences by starting ruminating on them. This type of thinking has also been referred to as metarumination (Papageorgiou \& Wells, 2003). Both rumination and NBRS uncontrollability and harm explained a significant proportion of the variance in depression scores. As the link between rumination and NBRS uncontrollability and harm was bi-directional, mediation of NBRS uncontrollability and harm in the relation between rumination and depression was not examined. Noteworthy, the S-REF model does not suggest that it is only negative metacognitive beliefs that mediate the relationship between rumination and depression, but negative beliefs about the self (activated during rumination) may also mediate this relationship. Future research should include the assessment of negative beliefs about the self.

A second aim of the current study was to extend the metacognitive model of rumination and depression with the concept of self-discrepancy. Results from the structural equation modelling provided support for the notion that the perception of various types of self-discrepancies (i.e., actual-ideal, actual-ought, and actualfeared) was associated with positive beliefs about rumination. Further, in line with our expectation, discrepancies between selves not only indirectly influenced depression scores via metacognitions and rumination, but also showed a direct link to depression. Wells and Matthews' (1994) S-REF model suggests additional possibilities such as a direct link from depression to self-discrepancy because emotion may signal a self-discrepancy in the model. This suggests that there could be a bi-directional link between depression and self-discrepancy. However, these possibilities were not tested in the present study and warrant further research. 
The results of this study are supportive of a "cognitive pathway" by which the effects of self-discrepancy can be transmitted to symptoms of depression. We further tested the extent to which positive beliefs about rumination would mediate the relation between self-discrepancy and rumination. For all types of selfdiscrepancy, partial mediation of positive beliefs about rumination was found, suggesting that at least part of the relation between self-discrepancy and rumination runs via positive beliefs about rumination, which may have key implications for the treatment of depression.

Clinical implications of the results of this study may be that a metacognitive-focused cognitive therapy of depression could include strategies specifically designed to modify positive and negative beliefs about rumination. Indeed, grounded on the S-REF model and the metacognitive treatment approach to generalized anxiety disorder (Wells, 1997), Wells and Papageorgiou (2004) have advocated the use of a specific metacognitive therapy for depressive rumination. The primary goals of this therapy include: (1) socializing patients to the idea that rumination and attentional monitoring for threat are a source of the problem; (2) facilitating abandonment of rumination; (3) enhancing flexible control over cognition through the use of attention training (Papageorgiou \& Wells, 2000; Wells, 1990, 2000), prescribed rumination ban, and detached mindfulness; (4) challenging positive and negative metacognitive beliefs about rumination; and (5) modifying negative beliefs about emotion that contribute to rumination/worry and fear of relapse. For instance, in a case series, attention training was associated with clinically significant decrements in depression, metacognitions, and rumination in patients with recurrent major depressive disorder and these changes were maintained at 12 months follow-up (Papageorgiou \& Wells, 2000). Another recent treatment development that is likely to be of relevance to changing rumination and metacognitions is mindfulness-based cognitive therapy, which is aimed at preventing relapse/recurrence in recovered depressed patients (Segal, Williams, \& Teasdale, 2002). As the current study underscores the role of self-discrepancies, interventions designed to alter self-discrepant feelings could also be useful. Self-System Therapy is a relatively new approach for treating depression that directly addresses self-discrepancies that can lead to depression (Vieth et al., 2003). This novel treatment has shown promising results, with overall efficacy comparable to cognitive therapy and superior efficacy for depressed individuals with significant problems in self-regulation and self-discrepant beliefs (see Vieth et al., 2003).

Admittedly, the current study has several drawbacks. First, the study was correlational in nature and it should be borne in mind that no firm conclusions on cause-effect relationships can be drawn. Longitudinal research in non-clinical as well as clinical samples is particularly welcome to substantiate the findings obtained in the current study. Second, the sample of the current study was predominantly female, which may limit the generalisability of the results to males. Finally, no screening took place as to whether participants met DSMIV criteria for major depressive disorder or other psychological disorders.

Despite these limitations, the results of the current study contribute to our understanding of the cognitive processes that are involved in explaining how self-discrepancies can be linked to depression. More specifically, self-discrepancies have a direct as well as an indirect effect (via cognitive processes involved in the metacognitive model of rumination and depression) on symptoms of depression. Negative beliefs about rumination concerning uncontrollability and harm may be involved in the maintenance of ruminative responses via the process of metarumination. In light of previous research, the results of the current study are supportive of the view that negative beliefs about rumination may be considered a vulnerability factor for depression. More investigations, in particular longitudinal research, are needed to further substantiate the links between self-discrepancies, metacognitions, rumination, and depressive symptoms in non-clinical as well as clinical populations.

\section{References}

Baron, R. M., \& Kenny, D. A. (1986). The moderator-mediator variable distinction in social psychological research: Conceptual, strategic, and statistical considerations. Journal of Personality and Social Psychology, 51, 1173-1182.

Bruch, M. A., Rivet, K. M., \& Laurenti, H. J. (2000). Type of self-discrepancy and relationships to components of the tripartite model of emotional distress. Personality and Individual Differences, 29, 37-44.

Higgins, E. T. (1987). Self-discrepancy: A theory relating self and affect. Psychological Review, 94, 319-340.

Higgins, E. T. (1999). When do self-discrepancies have specific relations to emotions? The second-generation question of Tangney, Neidenthal, Covert, and Barlow (1998). Journal of Personality and Social Psychology, 77, 1313-1317. 
Higgins, E. T., Bond, R. N., Klein, R., \& Strauman, T. (1986). Self-discrepancies and emotional vulnerability: How magnitude, accessibility, and type of discrepancy influence affect. Journal of Personality and Social Psychology, 51, 5-15.

Higgins, E. T., Roney, C. J., Crowe, E., \& Hymes, C. (1994). Ideal versus ought predictions for approach and avoidance: Distinct selfregulatory systems. Journal of Personality and Social Psychology, 66, 276-286.

Higgins, E. T., Shah, J., \& Friedman, R. (1997). Emotional responses to goal attainment: Strength of regulatory focus as moderator. Journal of Personality and Social Psychology, 72, 515-525.

Jöreskog, K. G., \& Sörbom, D. (1999). LISREL 8. 30. Chicago IL: Scientific software International Inc.

Luminet, O. (2004). Measurement of depressive rumination and associated constructs. In C. Papageorgiou, \& A. Wells (Eds.), Depressive rumination: Nature, theory and treatment (p. 187215). Chichester: Wiley.

Lyubomirsky, S., \& Tkach, C. (2004). The consequences of dysphoric rumination. In C. Papageorgiou, \& A. Wells (Eds.), Depressive rumination: Nature, theory and treatment (pp. 21-42). Chichester: Wiley.

Markus, H., \& Nurius, P. (1986). Possible selves. American Psychologist, 41, 954-969.

Martin, L. L., \& Tesser, A. (1996). Some ruminative thoughts. In R. S. Wyer (Ed.), Advances in social cognition, Vol. 9 (pp. 1-47). Mahwah, NJ: Lawrence Erlbaum.

Miskimins, R. W., \& Braucht, G. N. (1971). Description of the self. Fort Collins, Col.: RMBSI.

Moretti, M., \& Higgins, E. T. (1990). Relating self-discrepancy to self-esteem: The contribution of discrepancy beyond actual-self ratings. Journal of Experimental and Social Psychology, 26, 108-123.

Nolen-Hoeksema, S. (1991). Responses to depression and their effects on the duration of depressive episodes. Journal of Abnormal Psychology, 100, 569-582.

Nolen-Hoeksema, S., \& Morrow, J. (1991). A prospective study of depression and posttraumatic stress symptoms after a natural disaster: The 1989 Loma Preita earthquake. Journal of Personality and Social Psychology, 61, 115-121.

Nolen-Hoeksema, S. (1998). Ruminative coping with depression. In J. Heckhausen, \& C. S. Dweck (Eds.), Motivation and self-regulation across the life span (pp. 237-256). New York: Cambridge University Press.

Ogilvie, D. M. (1987). The undesired self: A neglected variable in personality research. Journal of Personality and Social Psychology, 52, 379-385.

Papageorgiou, C., \& Wells, A. (2000). Treatment of recurrent major depression with attention training. Cognitive and Behavioral Practice, $74,407-413$.

Papageorgiou, C., \& Wells, A. (2001a). Metacognitive beliefs about rumination in recurrent major depression. Cognitive and Behavioral Practice, 8, 160-164.

Papageorgiou, C., \& Wells, A. (2001b). Positive beliefs about depressive rumination: Development and preliminary validation of a selfreport scale. Behavior Therapy, 32, 13-26.

Papageorgiou, C., \& Wells, A. (2003). An empirical test of a clinical metacognitive model of rumination and depression. Cognitive Therapy and Research, 27, 261-273.

Papageorgiou, C., \& Wells, A. (2004). Depressive rumination: Nature, theory and treatment. Chichester: Wiley.

Raes, F., Hermans, D., \& Eelen, P. (2003). The Dutch version of the Ruminative Response Scale (RRS-NL) and the Rumination on Sadness Scale (RSS-NL). Gedragstherapie, 36, 97-104.

Rush, A. J., Trivedi, H., Ibrahim, H. M., Carmody, T. J., Arnow, B., Klein, D. N., et al. (2003). The 16-item Quick Inventory of Depressive Symptomatology (QIDS), Clinician Ratings (QIDS-C), and Self-Report (QIDS-SR): A psychometric evaluation in patients with chronic major depression. Biological Psychiatry, 54, 573-583.

Scott, L., \& O'Hara (1993). Self-discrepancies in clinically anxious and depressed university students. Journal of Abnormal Psychology, $102,282-287$.

Segal, Z. V., Williams, J. M. G., \& Teasdale, J. D. (2002). Mindfulness-based cognitive therapy for depression-A new approach to preventing relapse. New York: Guilford Press.

Sobel, M. E. (1982). Asymptotic confidence intervals for indirect effects in structural equation models. In S. Leinhart (Ed.), Sociological methodology 1982 (pp. 290-312). San Francisco: Jossey-Bass.

Strauman, T. J. (1989). Self-discrepancies in clinical depression and social phobia: Cognitive structures that underlie emotional disorders? Journal of Abnormal Psychology, 98, 14-22.

Tangney, J. P., Neidenthal, P. M., Covert, M. V., \& Barlow, D. H. (1998). Are shame and guilt related to distinct self-discrepancies? A test of Higgins' (1987) hypotheses. Journal of Personality and Social Psychology, 75, 256-268.

Vieth, A., Strauman, T. J., Kolden, G., Woods, T., Michels, J., \& Klein, M. H. (2003). Self-System Therapy (SST): A theory-based psychotherapy for depression. Clinical Psychology: Science and Practice, 10, 245-268.

Wells, A. (1990). Panic disorder in association with relaxation induced anxiety: An attentional training approach to treatment. Behavior Therapy, 21, 273-280.

Wells, A. (1997). Cognitive therapy of anxiety disorders: A practice manual and conceptual guide. Chichester, UK: Wiley.

Wells, A. (2000). Emotional disorders and metacognitions: Innovative Cognitive Therapy. Chichester, UK: Wiley.

Wells, A., \& Matthews, G. (1994). Attention and emotion: A clinical perspective. Hove, UK: Lawrence Erlbaum.

Wells, A., \& Papageorgiou, C. (2004). Metacognitive therapy for depressive rumination. In C. Papageorgiou, \& A. Wells (Eds.), Depressive rumination: Nature, theory and treatment (pp. 259-273). Chichester: Wiley. 